\title{
Primary Pulmonary Synovial Sarcoma: How to Expect the Unexpected?
}

\author{
Mayank Yadav, Sumit Pratap Singh, Mohd Azam Haseen, Braj Mohan Singh', Noor Ahmad Lari, Mohammed Haneef Beg² \\ Department of Cardiothoracic Surgery, J.N. Medical College, AMU, Aligarh, ${ }^{2}$ Department of General Surgery, F.H. Medical College, Tundla, Uttar Pradesh, ${ }^{1}$ Department \\ of Cardiothoracic Surgery, HCG Hospital, Bhavnagar, Gujarat, India
}

\section{Abstract}

Primary pulmonary synovial sarcoma (PPSS) is a rare and aggressive malignancy with a presentation similar to that of lung carcinoma. We present an 18-year-old male who presented with complaints of chest pain, cough, and hemoptysis. Physical examination and blood parameters were normal. Imaging studies revealed a large, well-defined, round homogeneous mass in the left lower lobe. His fine-needle aspiration cytology was suggestive of a round cell tumor. The patient was operated under general anesthesia through left posterolateral thoracotomy. The tumor was removed en masse and sent for histopathological examination. His histopathology and immunohistochemistry suggested PPSS of biphasic variety.

Keywords: Immunohistochemistry, primary pulmonary synovial sarcoma, space-occupying lesion of lung

\section{INTRODUCTION}

Primary pulmonary synovial sarcoma (PPSS) is a rare and aggressive malignancy with a presentation similar to that of lung carcinoma, which is the most common pulmonary neoplasm. ${ }^{[1]}$ Soft-tissue sarcomas present a diagnostic and therapeutic challenge as obtaining the initial accurate tissue diagnosis is very important for the treatment and prognostication of the patient. Immunohistochemistry is important not only for diagnosis but also to differentiate the poorly differentiated subtype of synovial cell sarcoma from the others through cell morphology. ${ }^{[1-3]}$ As the origin of synovial sarcoma is not associated with normal synovial tissues, it is presently grouped under miscellaneous soft-tissue tumors. ${ }^{[4]}$ The treatment of PPSS is diverse and nonstandard due to its rarity. Standard management strategy includes surgical resection, radiation therapy, and chemotherapy ${ }^{[5]}$ PPSS is locally aggressive with infrequent metastasis. The 5 -year mortality rate is approximately $50 \%$, which can be worse with tumors of size $>5 \mathrm{~cm}$ and a high mitotic rate. ${ }^{[6]}$ Here, we report a case of an 18 -year-old male, who presented with left-sided chest pain, cough with blood-tinged sputum, and was found to have PPSS of the lung.

\begin{tabular}{|l|l|}
\hline \multicolumn{2}{|c|}{ Access this article online } \\
\hline Quick Response Code: & Website: \\
\hline & www.ijrc.in \\
\hline & \\
\hline
\end{tabular}

\section{Case Report}

An 18-year-old nonsmoker male was referred to us with complaints of left-sided chest pain and cough with blood-tinged sputum. Physical examination revealed mild decreased air entry in left lung fields. His blood and biochemical parameters were normal. Posteroanterior chest X-ray [Figure 1] revealed a solitary, well-defined round homogeneous opacity in the left midzone with normal surrounding lung parenchyma. There was no evidence of any calcification. The rest of the bilateral lung fields were normal. Based on his chest X-ray findings, he had received albendazole for 2 months prescribed by a general practitioner, suspecting hydatid disease of the lung. Contrast-enhanced chest computed tomography (CT) confirmed a $6 \mathrm{~cm} \times 7 \mathrm{~cm} \times 6.5 \mathrm{~cm}$, well-defined, rounded, heterogeneously enhancing, solid, soft-tissue mass lesion involving the superior segment of the left lower lobe [Figure 1].

Address for correspondence: Dr. Mayank Yadav, Department of Cardiothoracic Surgery, J.N. Medical College, AMU, Aligarh, Uttar Pradesh, India. E-mail: undefinedmayank@gmail.com

This is an open access journal, and articles are distributed under the terms of the Creative Commons Attribution-NonCommercial-ShareAlike 4.0 License, which allows others to remix, tweak, and build upon the work non-commercially, as long as appropriate credit is given and the new creations are licensed under the identical terms.

For reprints contact: WKHLRPMedknow_reprints@wolterskluwer.com

How to cite this article: Yadav M, Singh SP, Haseen MA, Singh BM, Lari NA, Beg MH. Primary pulmonary synovial sarcoma: How to expect the unexpected? Indian J Respir Care 2021;10:136-8.

Received: $22-05-2020$

Accepted: 07-09-2020 Published: 31-01-2021 
The lesion was abutting oblique fissure anteriorly, compressing and displacing the left main lower lobe bronchus with normal adjacent lung parenchyma. Medially, the lesion was abutting inferior pulmonary vein with no evidence of any invasion or intraluminal filling defect. Posteriorly, the lesion was focally abutting costal pleura. There was no evidence of mediastinal or axillary adenopathy. CT finding of the rest of the thorax and abdomen was unremarkable. Bronchoscopy was done, which showed no endobronchial pathology. Endobronchial biopsy could not be taken owing to its distal location. The CT-guided fine-needle aspirate cytology revealed a round cell tumor.

Tumor resection en masse was done through left posterolateral thoracotomy. It was a large tumor bulging out at the superior segment of the left lower lobe with a thin layer of lung parenchyma over it. A small bronchus found communicating with the tumor cavity was oversewn, and marsupialization of the cavity was done with absorbable sutures. An intercostal tube drain (ICTD) was inserted and connected to the underwater seal. The patient recovered well, his ICTD was removed on the $3^{\text {rd }}$ postoperative day, and he was discharged on the $6^{\text {th }}$ postoperative day.

Histopathological examination of the large, well-circumscribed nodular mass of size $7 \mathrm{~cm} \times 8 \mathrm{~cm} \times 6.5 \mathrm{~cm}$ [Figure 2] showed spindle-shaped tumor cells with a moderate amount of pleomorphism, arranged in a storiform pattern with variably dilated spaces lined by cuboidal to columnar epithelial cells [Figure 3]. Immunohistochemically, tumor cells were positive for cytokeratin, epithelial membrane antigen (EMA), and vimentin. Thus, a final diagnosis of primary pulmonary biphasic spindle cell type SS was made.

The patient was advised left lower lobectomy, which he refused because he was asymptomatic. He was referred to the medical oncology department for chemotherapy and/or radiotherapy. He is under follow-up, and a positron emission tomography (PET) scan at 3 months showed no recurrence.

\section{Discussion}

Synovial sarcoma is a rare mesenchymal tumor, accounting for $10 \%$ of all soft-tissue sarcomas. The most common sites are the soft tissues around large joints, while head and neck, lung, heart, mediastinum, and abdominal wall are other rarer sites. ${ }^{[7]}$ The most common age of presentation is between the third and fifth decades with a slight male predilection. ${ }^{[6]}$ Although the tumor does not originate from synovial tissue, under light microscopy, it resembles a synovial tissue tumor.

This patient was a young male presenting with chest pain, cough, and hemoptysis. Some studies have also reported ipsilateral pleural effusion as a presenting feature in some cases of PPSS. ${ }^{[8]}$ Necrosis and hemorrhage are often reported, although this patient did not have them. ${ }^{[8]}$ Chest wall invasion may occur, although it was not there in our case.

PPSS shows less vascularity, hemorrhage, and necrosis on magnetic resonance as compared with soft-tissue synovial
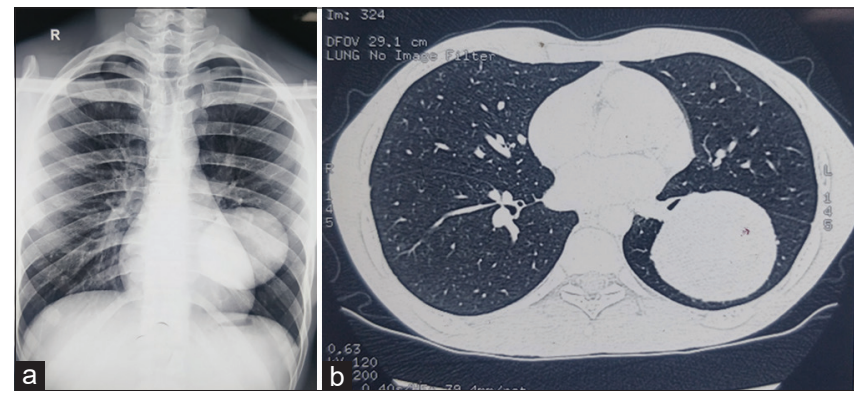

Figure 1: (a) ChestX-ray posteroanterior view shows a well-defined round single homogeneous mass in the left lower lobe. (b) Contrast-enhanced chest computed tomography thorax shows a well-defined round mass in the posterior basal segment with normal surrounding lung parenchyma in the left lower lobe. No evidence of any calcification/cystic areas or any other lung nodules

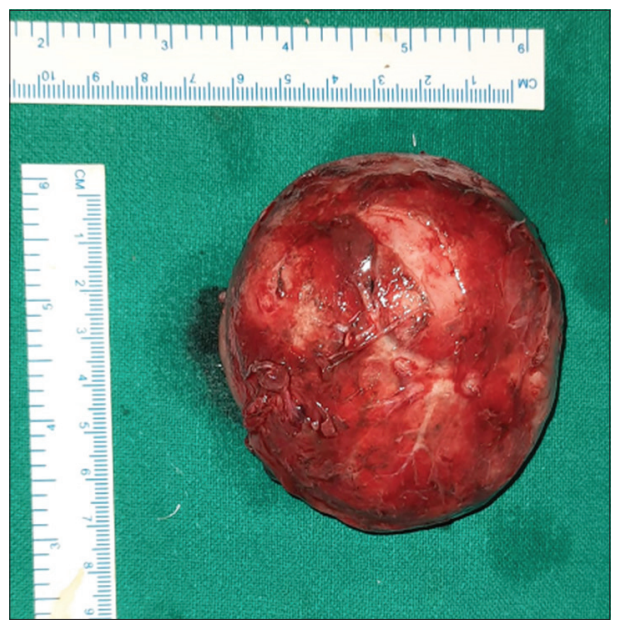

Figure 2: Gross tumor specimen showing a well-circumscribed nodular mass of size $7 \mathrm{~cm} \times 8 \mathrm{~cm} \times 6.5 \mathrm{~cm}$
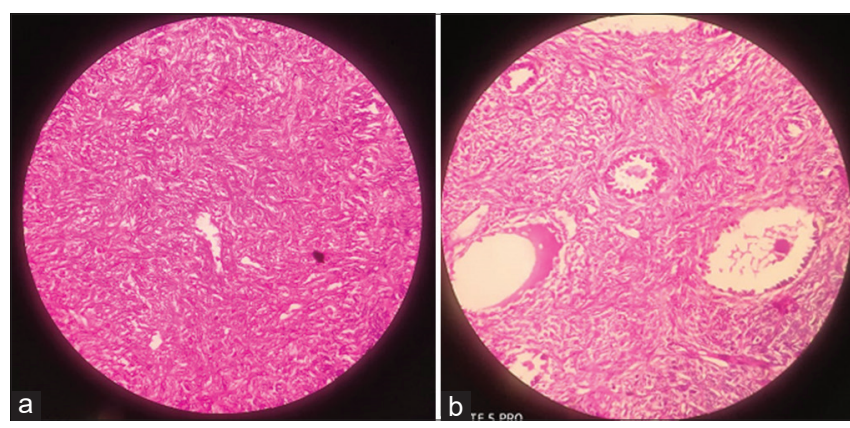

Figure 3: (a) $\mathrm{H}$ and $\mathrm{E}(\times 10)$ tumor cells arranged in storiform pattern with variably dilated spaces. (b) $\mathrm{H}$ and $\mathrm{E}(\times 40)$ spindle-shaped tumor cells showing a moderate amount of pleomorphism along with dilated spaces lined by cuboidal to columnar cells

sarcoma, which shows hemorrhage and blood fluid levels. Fine-needle aspiration cytology of lung mass may be inconclusive, especially in larger tumors. Hence, image-guided needle biopsy, open lung biopsy, or thoracoscopic biopsy is required to make the diagnosis. ${ }^{[6]}$ Unlike other pulmonary sarcomas, histologically, it is composed of two morphologically different cell lineages: epithelial cells and fibroblast-like spindle 
cells. On histolopathological examination, PPSSs can be categorized into four subtypes - monophasic fibrous (spindle), monophasic epithelial, biphasic, and poorly differentiated. ${ }^{[2]}$ Monophasic subtypes are the most common subtypes. Biphasic subtypes have both epithelial and spindle cell components. ${ }^{[6]}$

Monophasic fibrous variant is characterized by the predominance of spindle cells with small epithelial rests, whereas monophasic epithelial type exhibits the predominance of epithelial cells with the formation of gland-like structures..$^{[9]}$ Differentiation of monophasic subtypes from primary carcinomas of the lung is difficult. The diagnosis of poorly differentiated synovial sarcoma is very difficult as it is a crossover of all other variants. Due to its most aggressive nature, it has got the worst prognosis among all four variants. ${ }^{[6]}$ On immunohistochemistry, synovial sarcomas are uniformly positive for cytokeratin, EMAs, bcl-2, and vimentin and negative for S-100, desmin, smooth muscle actin, and vascular tumor markers. ${ }^{[2]}$ Differentiation between monophasic and biphasic forms is done by cytogenetic study using reverse transcriptase-polymerase chain reaction. Reciprocal chromosomal translocation (X; 18) (p11.2; q11.2) resulting from the fusion of SYT gene on chromosome 18 to either of two genes, SSX 1 and SSX 2 on chromosome X, is the characteristic of synovial sarcoma. ${ }^{[3]}$

SYT-SSX1 fusion transcript is more common in biphasic tumors, whereas SYT-SSX2 fusion transcript mostly occurs in monophasic tumors, with the latter having a better prognosis than the former. ${ }^{[2]}$ The current management strategy consists of wide local surgical excision, followed by adjuvant chemotherapy or radiotherapy. However, due to a small number of patients, there is no consensus regarding treatment protocol. Recurrences are common, so wide local surgical resection in patients with an otherwise long life expectancy is advocated, as the sensitivity on the frozen section is low. ${ }^{[6]}$ Lobectomy was not done initially as the diagnosis was confirmed only on biopsy of the resected specimen. The patient is under regular follow-up. A PET at 3 months did not show any recurrence.

Adjuvant chemotherapy with ifosfamide and doxorubicin has shown to improve the overall survival rate including time to local recurrence and recurrence-free survival rate. ${ }^{[5]}$ However, the rarity of this tumor is a hindrance in conducting a proper randomized trial for the safety and efficacy of chemotherapy in PPSS.

PPSS has a poor prognosis, with an overall 5-year survival rate of approximately $50 \%$. The tumor size, age of patient, extent of tumor necrosis, higher histological grade, male gender, mitotic rate, neurovascular invasion, and SYT-SSX1 variants are negative prognostic factors. ${ }^{[2]}$ Hence, the surgeon should be aggressive when dealing with PPSS and opt for saving life rather than lung. Moreover, a robust postoperative surveillance program is needed to detect and treat any recurrence. The patient must be explained about the aggressive nature of the tumor and its propensity to recur so that they come for regular follow-up.

\section{Conclusion}

The diagnosis of malignancy should be borne in mind when dealing with young patients presenting with space-occupying lesion of the chest, in addition to common diseases such as tuberculosis and hydatid disease of the lung. Clinical, radiological, pathological, and immunohistochemical investigations are required to confirm the diagnosis. Cytology may be unreliable, especially in huge pulmonary sarcomas, and histopathology is required to establish the diagnosis. Radiological investigations are needed to evaluate the extent of the tumor and to rule out any extrathoracic disease. Currently, the standard of treatment is aggressive surgical resection along with adjuvant chemoradiotherapy, although the long-term prognosis is poor. Postoperative tumor surveillance is of utmost importance to detect and treat recurrences.

\section{Declaration of patient consent}

The authors certify that they have obtained all appropriate patient consent forms. In the form, the legal guardian has given his consent for images and other clinical information to be reported in the journal. The guardian understands that names and initials will not be published and due efforts will be made to conceal identity, but anonymity cannot be guaranteed.

\section{Financial support and sponsorship}

Nil.

\section{Conflicts of interest}

There are no conflicts of interest.

\section{RefEREnCES}

1. Jiang J, Zhou J, Ding W. Primary pulmonary synovial sarcoma, a rare primary lung neoplasm: Two case reports and review of the current literature. Respirology 2008;13:748-50.

2. Dennison S, Weppler E, Giacoppe G. Primary pulmonary synovial sarcoma: A case report and review of current diagnostic and therapeutic standards. Oncologist 2004;9:339-42.

3. Clark J, Rocques PJ, Crew AJ, Gill S, Shipley J, Chan AM, et al. Identification of novel genes, SYT and SSX, involved in the $\mathrm{t}(\mathrm{X} ; 18)$ (p11.2;q11.2) translocation found in human synovial sarcoma. Nat Genet 1994; 7:502-8.

4. Weiss SW. Histological typing of soft tissue tumors. International Histological Classification of Tumors. $2^{\text {nd }}$ ed. Berlin: World Health Organization; 1994. p. 7-14.

5. Spillane AJ, A'Hern R, Judson IR, Fisher C, Thomas JM. Synovial sarcoma: A clinicopathologic, staging, and prognostic assessment. J Clin Oncol 2000;18:3794-803.

6. Bhattacharya D, Datta S, Das A, Halder KC, Chattopadhyay S. Primary pulmonary synovial sarcoma: A case report and review of literature. Int J Appl Basic Med Res 2016;6:63-5.

7. Mankin HJ, Hornicek FJ. Diagnosis, classification, and management of soft tissue sarcomas. Cancer Control 2005;12:5-21.

8. Frazier AA, Franks TJ, Pugatch RD, Galvin JR. From the archives of the AFIP: Pleuropulmonary synovial sarcoma. Radiographics 2006;26:923-40.

9. Zeren H, Moran CA, Suster S, Fishback NF, Koss MN. Primary pulmonary sarcomas with features of monophasic synovial sarcoma: A clinicopathological, immunohistochemical, and ultrastructural study of 25 cases. Hum Pathol 1995;26:474-80. 